\title{
Comment on "Lightning as a geomorphic agent on mountain summits: evidence from southern Africa" by Knight and Grab (2014)
}

\author{
Paul Douglas Sumner \\ Department of Geography, Geoinformatics and Meteorology \\ University of Pretoria, Private Bag X20, Hatfield, 0028, \\ SOUTH AFRICA \\ paul.sumner@up.ac.za \\ Tel: +27124202881
}

\begin{abstract}
:
Insights into the possible effect of lightning strikes on rock breakdown are presented by Knight and Grab (2014) from a summit area in the Lesotho highlands. Based on their findings, the authors challenge the association of angular debris with frost shattering and use this as a platform for directing critique against palaeo-geomorphic studies. While the lightning strike data are not questioned directly here, the palaeo-environmental context within which the paper is set, the portrayal of former findings and the assumptions regarding weathering mechanisms in Lesotho are commented on. Frost shattering is the centre of Knight and Grab's weathering critique but, contrary to that stated in their text, none of the cited authors invoke this process in Lesotho. Other weathering processes that are speculated upon are not specific to cold climates either and thus cannot be used in support of their argument. In terms of debris and block distribution, lightning will not account for the preferential location of relict blocks and debris below summits on south-facing slopes, or for the extensive valley floor accumulations that are documented in Lesotho. Knight and Grab also falsely portray former studies by implying that palaeoenvironmental inferences in the area are drawn from block origin or morphology alone when the climatic signatures were derived from integrated assessments. In a palaeo-context, the relative contribution of lightning to debris production under dryer and colder conditions, when convective thunderstorm activity in the highlands was likely reduced, is also questioned. The weathering context, as well as the critique that Knight and Grab direct at other studies on relict landforms, is thus shown as inappropriate.
\end{abstract}

Keywords: Lesotho; Lightning strikes; Frost shattering; Debris production; Periglacial processes; Openwork block accumulations 
Knight and Grab (2014) provide the most enlightening insights on a phenomenon that has not previously been considered as a weathering, or debris production, mechanism in the basalt highlands of southern Africa. Their study, on a particular summit area reaching $3395 \mathrm{~m}$ a.s.1. in eastern Lesotho, details eight probable lightning strike sites from a broader set of observations made through 'walking' and suggests an alternative mechanism for bedrock, scarp and block fracturing. The idea is refreshing given our uncertainty regarding rock breakup mechanisms in this area, however, I am deeply concerned with the way in which the authors present the geomorphic literature and situate their findings. The issues detailed here call into question the authors' portrayal of the geomorphic literature, particularly the weathering mechanisms described, and the application of lightning strikes to relict landforms in Lesotho.

In providing a context for their findings, Knight and Grab repeatedly refer to apparently 'frost shattered' angular debris documented in other studies on Lesotho. 'Frost shattering' is a recurring theme in their text and is noted directly or in the association with angular debris on some 17 occasions. It is written that "Previous investigations have largely attributed mountain top weathering in this region to frost shattering (e.g. Boelhouwers et al., 2002; Sumner, 2004[a]; Sumner et al., 2009)" (p. 64) and their final statements specify that "to make uncritical climatic inferences based on the presence of 'frost shattered debris' on mountain summits is wholly erroneous" (Abstract, p. 61 and see also p. 68). The weathering context is clearly stated but none of the references cited in support of their contention mention 'frost shattering' in their reports. Neither is 'frost shattered debris' noted or given as an outcome. In fact, going back over at least two decades of geomorphology articles, nowhere that this author could find is 'frost shattering' proposed as a current or former weathering mechanism in Lesotho. Some earlier work in southern Africa, mostly located outside of Lesotho, did invoked 'frost shattering' however such arguments were long since refuted by Hall $(1991,1992)$ both as a mechanism, as well as in the casual association with angular debris. Blocks and debris derived from 'frost action' and 'frost wedging' have been proposed locally but these weathering mechanisms have also been questioned (see e.g. Hall, 1992; Boelhouwers et al., 2002 p. 252; Grab et al., 2005 p. 479). This apparent oversight questions the central weathering context within which Knight and Grab place their findings locally.

Perhaps in mitigation, Knight and Grab refer to other 'climatically-mediated' processes. When detailing their field methods, Knight and Grab specify that "An important issue is how to distinguish unequivocally between angular debris produced by frost shattering and other cold- 
climate weathering processes (e.g., dilatation, thermoclastis, and wetting/drying cycles), and geomorphically-similar debris produced by lightning strikes" (p. 64). However, to associate these other weathering mechanisms specifically with cold-climates is erroneous. Wetting and drying as a weathering mechanism has no particular association with cold temperatures (moisture cycles are required but can be induced anywhere) while dilatation can potentially cause fracturing at any location where unloading, or pressure-release, occurs (see Bland and Rolls, 1998). The cause of unloading may be climatically-related, such as in deglaciation, (although that is hardly relevant here) but the weathering mechanism itself carries no climatic inference. Thermallyinduced fracturing can occur anywhere - consider the weathering products in hot deserts - and it is likely that the process is also not climatically-associated (Sumner et al., 2004). These processes thus carry no direct climatic signature and cannot be portrayed specifically as "predominantly cold-season phenomena" (Knight and Grab, p. 64). Regardless of any potential contribution by lightning, Knight and Grab's overall weathering context is thus in need of reconsideration.

A summit area is the focus of Knight and Grab's field assessment. Lightning strike sites are identified by debris, rock surfaces that are 'freshly-fractured' or 'unweathered' (p. 65) and from evidence for recent remagnetisation, although 'older' strikes are noted on page 67 to be more difficult to identify by this latter method alone. In contrast, their critique (on pages 67 and 68 in particular) is directed against studies interpreting relict valley-slope and -floor openwork block accumulations (Boelhouwers et al., 2002; Sumner, 2004a) set in the Last Glacial (maximum approximately 21-15 ka BP). Clearly this was a period of enhanced block production and slope mobility that is not comparable to today (see Sumner, 2004a p. 300), but when encompassing the areas below the summits, as Knight and Grab intrinsically do with their critique, a point that is evidently missed is the uneven geographic distribution of relict blocks in eastern Lesotho.

Lightning strike locations should essentially be random in directional-aspect on the landscape yet blocky products are found predominantly on southern slope aspects (see Grab, 1999; Boelhouwers et al., 2002; Sumner, 2004a). Knight and Grab's strike records (Fig. 1B, p. 63) from their summit area confirm no such contemporary aspect bias that can explain this former debris- or block-distribution phenomenon.

Since no evidence is presented by Knight and Grab for strikes below the summit area it is particularly difficult to envisage this mechanism accounting for blocks comprising the valleyfloor blockstreams and blockfields described by Boelhouwers et al. (2002) and Sumner (2004a). 
If strikes do occur below summits, impacts on or within existing debris (see Knight and Grab p. 67 and Fig. 5) should also provide a distinct range of block and debris sizes, as well as fresh weathering surface attributes, downslope from the scarps as strikes further reduce debris. However, such attributes are not evident in the valley-wide records of, for example, Boelhouwers et al. (2002). It is unfortunate that Knight and Grab provide no product-size attribute data for direct contrast (actual measurements of debris size), which is a curious omission given the forceful reinterpretation invoked in their text. Perhaps strikes are mainly confined to summit areas, hence the specific location of Knight and Grab's field investigation, but if so then the critique of Boelhouwers et al. (2002) and Sumner (2004a) is inappropriate. A final point regarding their palaeo-context pertains to the climatic setting. During the Last Glacial, conditions in Lesotho were cooler and dryer overall. Cold fronts were thought to be more frequent but summers dryer (Mills et al., 2012) and thus it is likely that the incidence of convective thunderstorms and associated lightning strikes was significantly less. Alternatively, if the contextual setting of Knight and Grab lies in the wetter and warmer late Holocene, as described on page 68 , then the aforementioned critique is again misplaced. The overall contribution of lightning to rock breakdown and relict landforms is thus in need of careful consideration.

In addition to the contextual issues outlined above, Knight and Grab misrepresent several other studies. Sumner et al. (2004) cited on page 61 do not refer to any of the weathering processes in the preceding sentence. Perhaps Knight and Grab are associating "thermal expansion" (p. 61) with the possibility of fatigue as noted by Sumner et al. (2004) but this is inappropriate if one again considers the weathering mechanisms in detail. Neither do Hall et al. (2012) in the same paragraph endorse any of the specified processes but, to the contrary, argue against climaticallymediated weathering scenarios; a point that is later acknowledged by Knight and Grab (p. 62) but then immediately discarded. Sumner and Nel (2006), cited on page 67, are taken out of context. They provide contemporary temperature data from 1920m a.s.1. in the Drakensberg in South Africa that cannot be related to either current or former temperatures on the highlands above $3000 \mathrm{~m}$, or to relict deposits found there. While these errors may simply be overlooked they are in need of correction both for the sake of accuracy and to highlight what appears to be, as we shall further see, a persistent mis-portrayal of others' work.

In their discussion section Knight and Grab make strong statements that are especially in need of comment. Sumner (2004a) is given as the example of circular reasoning, based (apparently) on him using arguments from unambiguous periglacial environments elsewhere that are 
characterised by 'frost shattering' and by interpreting "surface morphology alone"; a point attributed to Sumner that is unequivocally noted as "entirely false" (p. 68). Knight and Grab then proceed to state in emphatic terms that "Such circular reasoning over the last decades has paralysed any progressive debate on the interpretation of mountain landform evolution in southern Africa" (p. 68, emphasis mine). Two comments are made here in response. First, any context of 'frost shattering' can be discarded as noted above but in broad reference to findings adopted from elsewhere, studies in southern Africa on relict and active periglacial landforms should (and do) draw from definite type examples. Without this, research in this marginal periglacial area would have little context. There are numerous examples of such an approach locally, including the findings for block and debris deposits being contextualised through reference to type-sites outside of southern Africa (Grab, 1999); relict sorted forms and possible mechanisms for their formation compared with attributes and theories from other known periglacial and permafrost environments (Grab, 2002); and several others, especially when considering marginal glacial evidence (see e.g. Mills and Grab, 2005; Hall, 2010). To draw from and contrast with findings from known unambiguous sites does not contribute to a circular line of reasoning but, when used correctly (see final comments below), constitutes sound scientific deduction and contextualisation.

Second, Knight and Grab refer twice to morphological attributes on page 68, notably the use of "morphology alone" upon which Sumner (2004a) is cited as deriving "climatic and environmental inferences." To state that his interpretation is based on morphology is an incomplete portrayal of the original report. Sumner (2004a) finds a periglacial signature expressed in the slope and valley floor block accumulations. His conclusion is derived from relative-age dating, block fabrics and evidence for former ground frost and slope mobility interpreted in the context of findings from elsewhere. Perhaps Knight and Grab were alluding to the attributes of the blocks themselves (ie angularity) when writing about 'morpholology' but this is in any case dispelled because the blocks comprising the relict openwork units are not described as angular, but as "sub-angular to sub-rounded" (Sumner, 2004a, p. 292). It is also noted (Sumner, 2004a, p. 292 and again on p. 299) that very few scarps at the site show contemporary mechanical fracturing or scree production - a point that is evidently overlooked by Knight and Grab and one that is in direct contrast to the proposed widespread contemporary application of lightning strikes and associated debris production. 
Given the above, Knight and Grab's accusation of circular reasoning, directed primarily at Sumner (2004a), that has supposedly paralysed progress in this area is dispelled. Conflicting opinions on the palaeo-geomorphology of Lesotho have raised much debate in the past and evidence for circular arguments, self-fulfilment and poorly adopted findings are given elsewhere (see Sumner, 2004b and Hall, 2012 for more recent discussions). Readers interested in the geomorphology of the Lesotho highlands can thus derive their own conclusions and, hopefully, provide new data that takes our understanding forward. However, until further data and explanation are available, the application of lightning strikes to relict landforms and thus their contribution to the geomorphic development of the highlands is best considered for now as speculative.

\section{References}

Bland, W., Rolls, D., 1998. Weathering: An Introduction to the Scientific Principles. Arnold, London.

Boelhouwers, J.C., Holness, S., Meiklejohn, K.I., Sumner, P.D., 2002. Observations on a blockstream in the vicinity of Sani Pass, Lesotho Highlands. Permafrost and Periglacial Processes 13, 251-257.

Grab, S.W., 1999. Block and debris deposits in the high Drakensberg, Lesotho, southern Africa: implications for high altitude slope processes. Geografiska Annaler 81A, 1 - 16.

Grab, S.W., 2002. Characteristics and palaeoenvironmental significance of relict sorted patterned ground, Drakensberg plateau, southern Africa. Quaternary Science Reviews 21, 1729-1744.

Grab, S.W., Van Zyl, C., Mulder, N. 2005. Controls on basalt terrace formation in the eastern Lesotho highlands. Geomorphology 67, 473-485.

Hall, K.J., 1991. The allocation of the freeze-thaw weathering mechanism in geocryological studies: a critical comment. South African Geographical Journal 73, 10-13.

Hall, K.J., 1992. A discussion on the need for greater rigour in southern African cryogenic studies. South African Geographical Journal 74, 69-71. 
Hall, K., 2010. The shape of glacial valleys and implications for southern African glaciation. South African Geographical Journal 92, 35-44.

Hall, K.J., 2012. A reply to Dr Knight in regard to his comments relating to 'The shape of glacial valleys and implications for southern African glaciation' (Hall 2010). South African Geographical Journal 94, 4-8.

Hall, J.J., Thorn, C., Sumner, P.D., 2012. On the persistence of 'weathering'. Geomorphology 149-150, 1-10.

Knight, J., Grab, S.W., 2014. Lightning as a geomorphic agent on mountain summits: evidence from southern Africa. Geomorphology 204, 61-70.

Mills, S.C., Grab, S.W., 2005. Debris ridges along the southern Drakensberg escarpment as evidence for Quaternary glaciation in southern Africa. Quaternary International 129, 61-73.

Mills, S.C., Grab, S.W., Rea, B.R., Carr, S.J., Farrow, A., 2012. Shifting westerlies and precipitation patterns during the Late Pleistocene in southern Africa determined using glacier reconstruction and mass balance modelling. Quaternary Science Reviews 55, 145-159.

Sumner, P.D., 2004a. Geomorphic and climatic implications of relict openwork block accumulations near Thabana-Ntlenyana, Lesotho. Geografiska Annaler 86A, 181-194.

Sumner, P.D., 2004b. Comment on: "Characteristics and palaeoenvironmental significance of relict sorted patterned ground, Drakensberg plateau, southern Africa'' by S.W. Grab. Quaternary Science Reviews 23, 1201-1204.

Sumner, P.D., Meiklejohn, K.I., Nel, W., Hedding, W., 2004. Thermal attributes of rock weathering: zonal or azonal? Polar Geography 28, 79-92.

Sumner, P.D., Nel, W., 2006. Surface-climate attributes at Injisuthi Outpost, Drakensberg, and possible ramifications for weathering. Earth Surface Processes and Landforms 31, 1445-1451. 
Sumner, P.D., Hall, K.J., van Rooy, L., Meiklejohn, K.I. 2009. Rock weathering on the eastern mountains of southern Africa: Review and insights from case studies. Journal of African Earth Sciences 55, 236-244. 